\title{
RESUMEN.
}

El aumento del índice de percepción de la corrupción, entregado por la última encuesta de la ONG Transparencia Internacional (TI), revela la importancia en la implementación de un sistema de control interno, enfocado en elaborar herramientas de consulta permanente sobre aspectos de probidad y transparencia institucional. Es por esto que el propósito de la presente investigación es el análisis en la gestión de riesgos de fraude al interior de un órgano público de la Región de Valparaíso en el Marco del Libro COSO II durante el período 2014. Se procedio en primer lugar a identificar los riesgos que generan potenciales fraudes, luego explicando las situaciones de riesgo mediante la construcción de una matriz estratégica de riesgo y finalmente determinando las actividades asociadas al proceso de gestión a aplicar para mitigar los riesgos de fraude. Se llego a concluir que la tendencia es favorable respecto al cumplimiento del levantamiento de los procesos, subprocesos y etapas críticas que presentan situaciones de riesgos

Palabras Claves: Corrupción, Sistema Control Interno, Probidad, Transparencia, Gestión de Riesgos.

\section{ANÁLISIS EN LA GESTIÓN DE RIESGOS DE FRAUDE A UNA INSTITUCIÓN PÚBLICA EN EL MARCO DEL LIBRO COSO II, PERÍODO 2014-2015.}

\section{ANALYSIS IN MANAGING FRAUD RISKS TO THE GOVERNMENT INSTITUTION IN THE FRAME OF THE COSO II BOOK, PERIOD 2014-2015.}

\section{ABSTRACT.}

The increase of the perception index of corruption, given by the last ONG International Transparency (TI) survey, reveals the importance of developing an internal control system focused on the elaboration of permanent consulting tools about probity aspects and institutional transparency. This is why the purpose of the present research is to make an analysis in managing fraud risks within a public institution of the region of Valparaíso in the frame of the COSO II book during the period 2014. To begin with, the risks, which generate potential fraud, were identified; then risky situations were explained by building a strategic matrix of risk, and finally, activities associated to the managing process to be applied so as to mitigate fraud risks were determined. Thus, it was then concluded that the tendency is favorable with respect to the execution of the lifting of processes, sub-processes and critical stages which present risky situations.

Key Words: Corruption, Internal Control System, Probity, Transparency, Risk Managing. 
Revista de Investigación Aplicada en Ciencias Empresariales 


\section{PROPÓSITO DEL ESTUDIO}

Los resultados entregados por la última encuesta de la ONG Transparencia Internacional (TI), sobre el índice de percepción de la corrupción, instrumento que permite clasificar a los países de acuerdo a los niveles de corrupción percibidos en el sector público, posiciona a Chile en el lugar 22 a nivel mundial y baja a la segunda posición en Latinoamérica, con menores niveles de corrupción. De acuerdo al estudio se analizaron durante el año 2013 a 177 países y más de la mitad de los encuestados cree que la corrupción ha empeorado en los últimos dos años. En este contexto y con la finalidad de que los servicios e instituciones del Estado mejoren sus procesos de gestión de riesgos implementados, así como también para poder determinar si las políticas, procedimientos y controles aplicados son efectivos para reducir los casos de fraude, es indispensable contar con herramientas necesarias que faciliten la toma de decisiones, para alcanzar los más altos niveles de probidad mediante una sólida estructura integrada entre el sistema de control interno y una administración enfocada a generar, mantener y mejorar estrategias de gestión de los riesgos de fraude.

Precisamente esta investigación tiene como finalidad el análisis en la gestión de riesgos de fraude de una institución pública regional en el Marco del Libro COSO II, período 2014.

\section{MARCO TEÓRICO}

\section{Fraude}

Las Normas de Auditoria Interna №3 Emitida por el Colegio de Contadores Chile A.G. ha definido el Fraude como "Cualquier acto ilegal caracterizado por engaño, ocultación 0 violación de confianza. Estos fraudes son perpetrados sin violencia física por individuos 0 por organizaciones para apropiarse en forma indebida de dinero, bienes 0 servicios, para evitar pagos, pérdidas de servicios 0 para asegurarse ventajas personales 0 de negocio". (Colegio de Contadores de Chile A.G, 2012; 14)

Además las Normas de Auditoría Generalmente Aceptadas; lo define como "Un acto intencional por parte de una o más personas de la Administración, encargados del Gobierno Corporativo, empleados o terceros, involucrando la utilización del engaño lo cual resulta en una representación incorrecta en estados financieros sometidos a una auditoría". (NAGA 63 Sección 240, 2012; 5) 


\section{Tipos de Fraudes}

Fraudes Internos: Son aquellos "organizados por una o varias personas dentro de una empresa, con el fin de obtener beneficio propio. Por lo general, se realizan con la intención de cometer malversación de activos de la empresa y, para ello, se valen de su cargo dentro de la organización o de la información que administran." (Labrada, 2010; 161)

Fraudes Externos: Son aquellos que se "efectúan por una 0 varias personas para obtener un beneficio, utilizando fuentes externas como bancos, clientes, proveedores, entre otros. Este tipo de fraudes puede involucrar esquemas tales como reclamaciones fraudulentas." (Labrada, 2010; 161)

Los Fraudes más comunes en las empresas se pueden agrupar en tres categorías:

- Apropiación de activos: Aquel empleado que desvía fondos de la empresa para su propio beneficio.

- Manipulación contable: Aquella que se realiza para la consecución de algunos objetivos.

- Corrupción: Aquellos casos en los que reciben o pagan tratos de favor para la adjudicación de un producto o servicio.

\section{Concepto de Control Interno}

"El Control Interno se define como un proceso efectuado por el consejo de administración, la administración y el resto del personal de una entidad, diseñado con el objetivo de proporcionar un grado de seguridad razonable en cuanto a la consecución de los objetivos." (Cepeda, G, 1997; 14)

\section{Antecedentes del COSO II}

En septiembre de 2004 se publica el Enterprise Risk Management (ERM) y sus aplicaciones técnicas asociadas, denominado COSO II, el cual amplia el concepto de control interno, proporcionando un foco más robusto y extenso sobre la identificación, evaluación y gestión integral de riesgo. Dando inicio de esta manera a un proyecto para desarrollar una estructura conceptualmente profunda que suministrara principios integrados, terminología común y orientación para la implantación práctica que permitan dar soporte a los programas de las entidades tendientes a desarrollar o hacer comparación de sus procesos de gestión de 
riesgos. Esta estructura resultante tendrá como objetivo asociado servir de base común para gerentes, directores, reguladores, académicos, entre otros, para comprender mejor la administración de los riesgos, sus beneficios y limitaciones y para comunicarse eficazmente.

\section{Objetivos del ERM}

El presente Marco de gestión de riesgos corporativos está orientado a alcanzar los objetivos de la entidad, que se pueden clasificar en cuatro categorías:

- $\quad$ Estrategia: Objetivos a alto nivel, alineados con la misión de la entidad.

- $\quad$ Operaciones: Objetivos vinculados al uso eficaz y eficiente de recursos.

- Información: Objetivos de fiabilidad de la información suministrada.

- Cumplimiento: Objetivos relativos al cumplimiento de leyes y normas aplicables.

Esta clasificación de los objetivos de una entidad permite centrarse en aspectos diferenciados de la gestión de riesgos corporativos. En el "ámbito de estas categorías distintas, un objetivo individual puede incidir en más de una categoría si se dirigen a necesidades diferentes de la entidad y pueden ser de responsabilidad directa de diferentes ejecutivos." (Sponsoring Organizations of the Treadway Commission, 2004; 1)

Dado que los objetivos relacionados con la fiabilidad de la información y el cumplimiento de leyes y normas están integrados en el control de la entidad, puede esperarse que la gestión de riesgos corporativos facilite una seguridad razonable de su consecución. El logro de los objetivos estratégicos y operativos, sin embargo, está sujeto a acontecimientos externos no siempre bajo control de la entidad. Respecto a ellos, la gestión de riesgos corporativos puede proporcionar una seguridad razonable de que la dirección, y el consejo de administración en su papel de supervisión, estén siendo informados oportunamente del progreso de la entidad hacia su consecución. (Sponsoring Organizations of the Treadway Commission, 2004; 1)

\section{Componentes de la Gestión de Riesgos Corporativos}

La gestión de riesgos corporativos consta de ocho componentes relacionados entre sí, que se derivan de la manera en que la dirección conduce la empresa y 
cómo están integrados en el proceso de gestión.

1) Ambiente interno: El Ambiente Interno abarca el conocimiento de una organización, que influye en la toma de conciencia de sus empleados sobre el riesgo y forma la base de los otros componentes de la gestión de riesgos corporativos, proporcionando disciplina y estructura.

2) Establecimiento de objetivos: Los objetivos se establecen antes de que la dirección pueda identificar potenciales eventos que afecten a su consecución. La gestión de riesgos corporativos asegura que la dirección ha instituido un proceso para fijar objetivos y que los objetivos seleccionados apoyan la misión de la entidad y están en línea con ella, además de ser consecuentes con el riesgo aceptado.

3) Identificación de eventos: Los acontecimientos internos y externos que afectan a los objetivos de la entidad deben ser identificados, diferenciando entre riesgos y oportunidades. Estas últimas revierten hacia la estrategia de la dirección o los procesos para fijar objetivos.

4) Evaluación de riesgos: Los riesgos se analizan considerando su probabilidad e impacto como base para determinar cómo deben ser gestionados y se evalúan desde una doble perspectiva, inherente y residual.

5) Respuesta al riesgo: La dirección selecciona las posibles respuestas evitar, aceptar, reducir o compartir los riesgos - desarrollando una serie de acciones para alinearlos con el riesgo aceptado y las tolerancias al riesgo de la entidad.

6) Actividades de control: Las actividades de control son las políticas y procedimientos que ayudan a asegurar que se lleven a cabo las respuestas de la dirección a los riesgos. Las actividades de control tienen lugar a través de la organización, en todos los niveles y en todas las funciones.

7) Información y comunicación: La información pertinente se identifica, capta y comunica, en un marco de tiempo que permiten a las personas llevar a cabo sus responsabilidades. Los sistemas de información usan datos generados internamente, entradas de fuentes externas y salidas informativas, que facilitan la gestión de riesgos y la toma decisiones informadas relativas a los objetivos.

8) Supervisión: La gestión de riesgos corporativos se supervisará, revisando la presencia y funcionamiento de sus componentes a lo largo del tiempo, llevando a cabo actividades permanentes de supervisión y evaluaciones independientes o una combinación de ambas técnicas. (Sponsoring 
Organizations of the Treadway Commission, 2004;1)

\section{Norma Chilena NCh-ISO 31000:2012 Gestión del riesgo, Principios y Orientaciones.}

El Instituto Nacional de Normalización, INN, es el organismo que tiene a su cargo el estudio y preparación de las normas técnicas a nivel nacional. Es miembro de la International Organization For Standardization (ISO) y de la Comisión Panamericana de Normas Técnicas (COPANT). Esta norma puede utilizarse por cualquier empresa pública, privada 0 social. Por tanto, esta norma no es específica de una industria 0 sector determinado. Además se puede aplicar a lo largo de toda la vida de una organización, y a una amplia gama de actividades, incluyendo estrategias y decisiones, operaciones, procesos, funciones, proyectos, productos, servicios y activos.

Principios: Mientras todas las organizaciones gestionan el riesgo en algún grado, esta norma establece principios que se deberían cumplir en todos sus niveles, para que la gestión del riesgo sea eficaz. 
Figura N5: Esquema "Principios del proceso de gestión de riesgos"

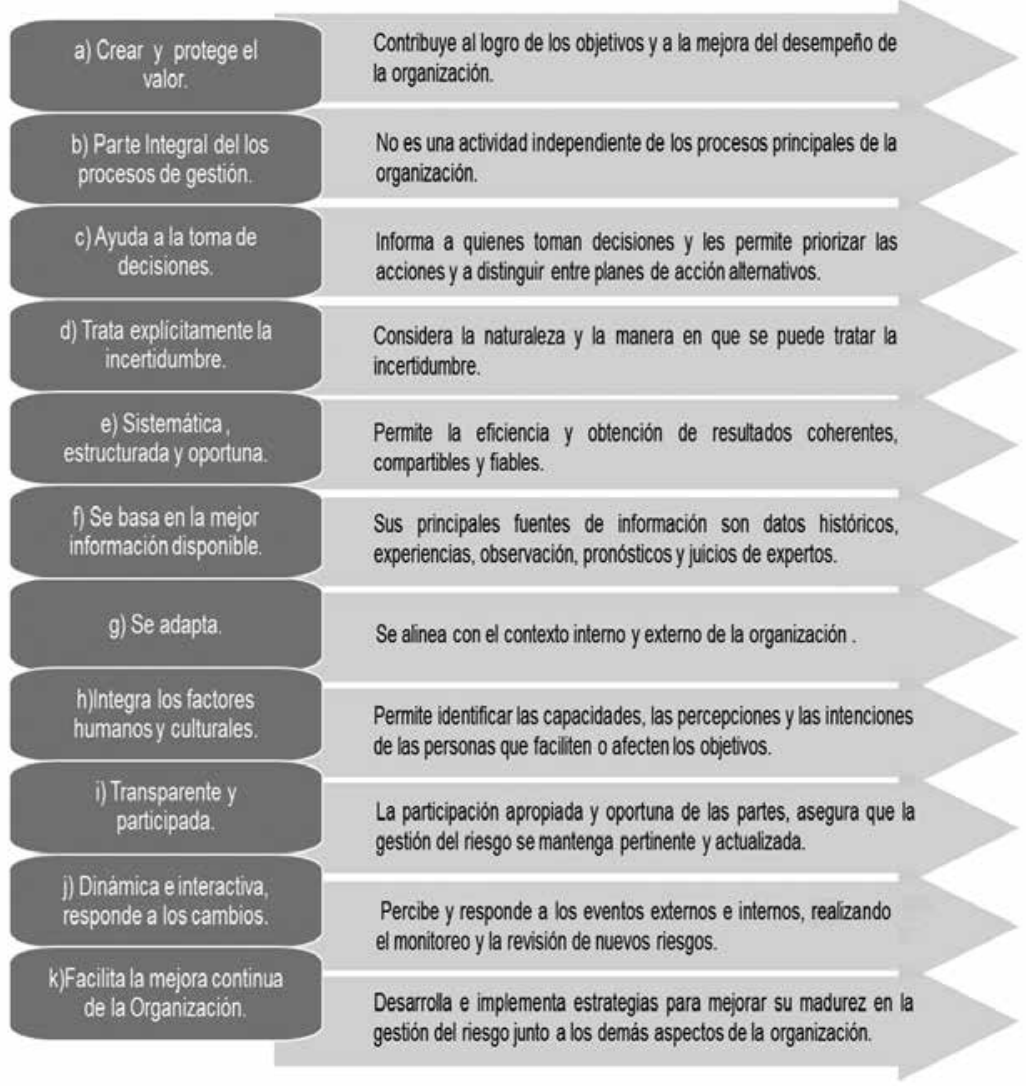

Fuente: Norma Chilena NCh-ISO 31000:2012 Gestión del riesgo - Principios y orientaciones.

\section{Actividades que comprenden el Proceso de Gestión de Riesgos.}

\section{FASE 1 "Establecimiento del Contexto"}

En esta fase se define el contexto organizacional y estratégico en los cuales tendrá lugar el Proceso de Gestión de Riesgos.

\section{FASE 2 "Identificación del Riesgo"}

Esta fase contempla la identificación de los riesgos como también de las oportunidades, que son definidos como un incidente 0 evento que emana de fuentes internas 0 externas que afectan al logro de los objetivos.

\section{FASE 3 "Análisis del Riesgo"}

Después de desarrollar la identificación de riesgos y su clasificación se procede a 
analizarlos, considerando los riesgos en relación a su probabilidad y consecuencias.

\section{FASE 4 "Valoración del Riesgo"}

Para la valoración de los Riesgos se consideran dos pasos. Primero la confirmación del criterio que se escogerá y segundo la confección de un ranking de riesgos en la organización.

\section{FASE 5 "Tratamiento del Riesgo"}

El tratamiento del riesgo requiere de la participación de la dirección e implica que debe tomar todas las acciones necesarias en forma concreta para administrar los riesgos una vez que han sido analizados y priorizados en el ranking de riesgos.

\section{FASE 6 "Monitoreo y Revisión”}

En esta fase es necesario nombrar responsables de monitorear la efectividad de todos los pasos del Proceso de Gestión de Riesgos, para asegurar que se está cumpliendo adecuadamente y que las circunstancias cambiantes no alteran las prioridades al afectar las ponderaciones estratégicas, las probabilidades o impactos de los riesgos, etc.

\section{FASE 7 "Comunicación y Consultas"}

Esta fase se desarrolla a través de la comunicación, información y consulta con los interesados. La información es identificada, capturada y comunicada de manera que todos puedan cumplir con sus responsabilidades.

\section{Metodología}

El paradigma de investigación se realiza en base a una metodología cualitativa con un enfoque de sintetización, con apoyo de una herramienta cuantitativa. Los instrumentos consisten en cuestionarios basados en los criterios de libro Coso II a fin de determinar la situación actual que presenta el servicio público en estudio, respecto a los riesgos que generan potenciales fraudes, y la aplicación de una matriz de riesgos estratégicos para proporcionar las principales situaciones de potenciales riesgos. 


\section{Resultados, discusión y conclusiones}

De acuerdo a la información proporcionada por los cuestionarios, respecto a los riesgos que generen potenciales situaciones de Fraude al interior de la institución en estudio, basado en los criterios del Libro Coso II, se realizó el levantamiento de la información en tablas, que permitían tabular, graficar, analizar y discutir los resultados obtenidos en las dos primeras preguntas, que se presentan a continuación:

I. Según su experiencia, al analizar los riesgos bajo lo establecido en la Guía Técnica №59

\section{Grafico $\mathrm{N}^{\circ}$ 1: Identifica el contexto organizacional y estratégico del Proceso de Gestión de Riesgos.}

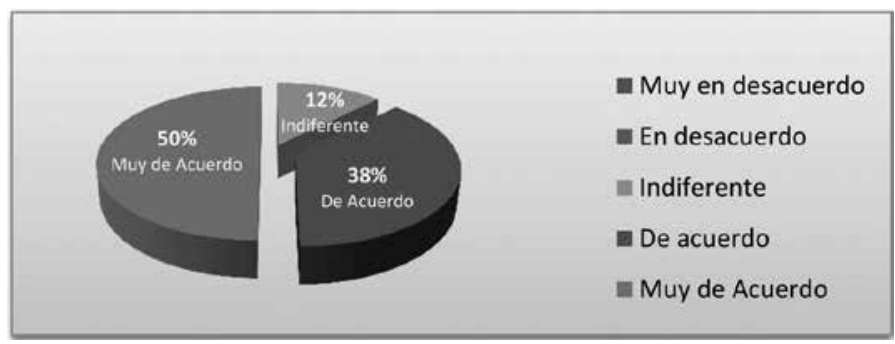

Fuente: Resultados del cuestionario en base al Libro Coso II. Elaboración Propia

Al consultar por la identificación del contexto organizacional donde se generan situaciones potenciales de riesgos, un porcentaje significativo del 88\% afirma estar de acuerdo 0 muy de acuerdo, y tan un solo un $12 \%$ considera que es indiferente el contexto donde se puede desarrollar el mismo, lo que deja en evidencia que los funcionarios tienen conocimiento de aquellas áreas estratégicas que consideran en su proceso de gestión de riesgos, lo cual es muy favorable ya que esta actividad permite identificar los parámetros internos cuando se gestiona el riesgo.

\section{Grafico N²: Identificación y Reconocimiento del riesgo.}

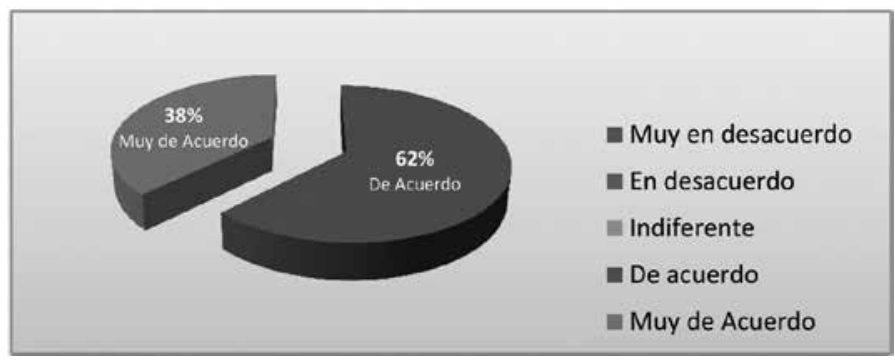

Fuente: Resultados del cuestionario en base al Libro Coso II. Elaboración Propia. 
Respecto a la identificación, búsqueda y reconocimiento de aquellas situaciones de riesgos que se pueden generan al interior de la institución en estudio, existe una tendencia clara, con un del $62 \%$ y $38 \%$ afirma estar de acuerdo y muy de acuerdo respectivamente.

\section{Grafico №3: Análisis de la naturaleza y nivel del riesgo}

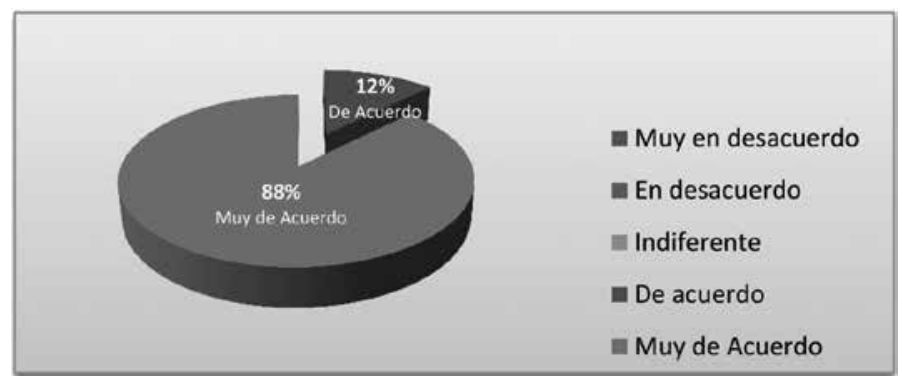

Fuente: Resultados del cuestionario en base al Libro Coso II. Elaboración Propia.

El análisis del riesgo implica conocer las causas, consecuencias y probabilidades de ocurrencia, en este caso, que un porcentaje significativo afirme estar muy de acuerdo, establece que existen herramientas y técnicas para la identificación del riesgo que se adaptan a sus objetivos.

\section{Grafico $\mathrm{N}^{\circ} 4$ : Ordenar y priorizar mediante un ranking los riesgos.}

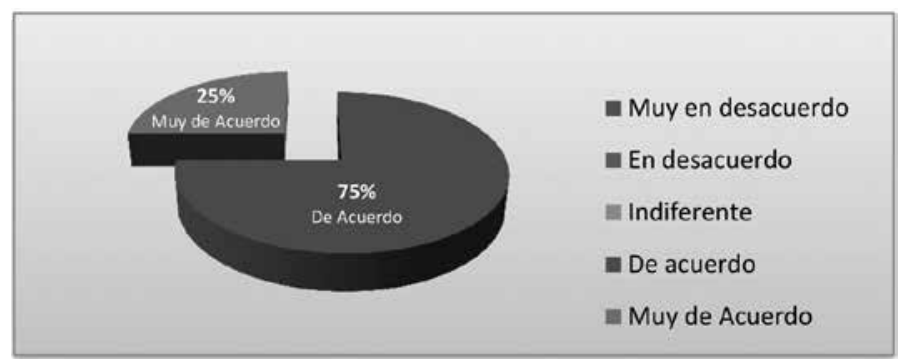

Fuente: Resultados del cuestionario en base al Libro Coso II. Elaboración Propia.

La finalidad de la valorización es ayudar a la toma de decisiones, determinando los riesgos a tratar y la prioridad para implementar el tratamiento, por lo tanto, si un $75 \%$ y $25 \%$ está de acuerdo y muy de acuerdo respectivamente, asevera que se efectúan mecanismos para ordenar y priorizar mediante un ranking. 


\section{Grafico N5: Determinar un tratamiento y/o monitoreo.}

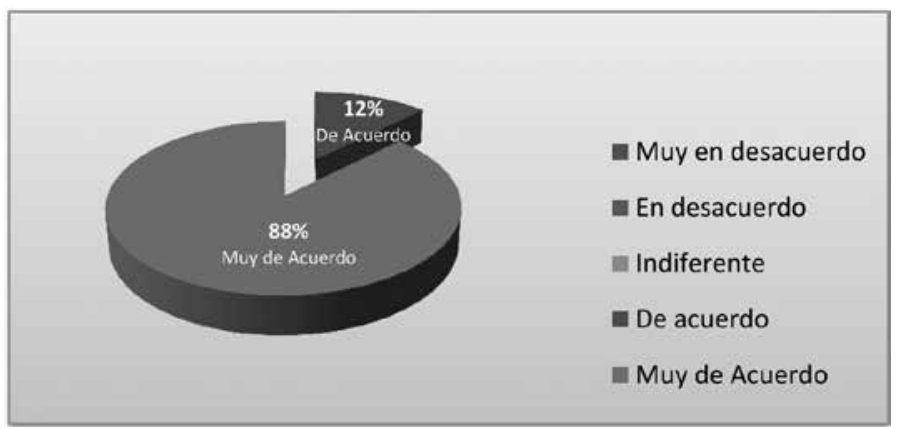

Fuente: Resultados del cuestionario en base al Libro Coso II. Elaboración Propia

El tratamiento del riesgo involucra obtener un equilibrio entre los costos y los esfuerzos de implementación, frente a las ventajas que se obtengan, teniendo en cuenta que un $88 \%$ y $12 \%$ afirman estar de acuerdo y muy de acuerdo respectivamente, confirma que se desarrollan e implementan estrategias, que mantengan el riesgo dentro de los niveles aceptados por la organización.

La primera parte del cuestionario permite afirmar que los funcionarios de la institución en estudio identifican la fuente de los riesgos, los eventos, sus causas y sus potenciales consecuencias como lo establece el Libro Coso II. Se puede apreciar además que cuentan con procesos destinados al tratamiento del riesgo.

\section{En la preparación de la Matriz de Riesgos Estratégicos}

Grafico ํ6: Identifica los procesos que desempeña el Servicio.

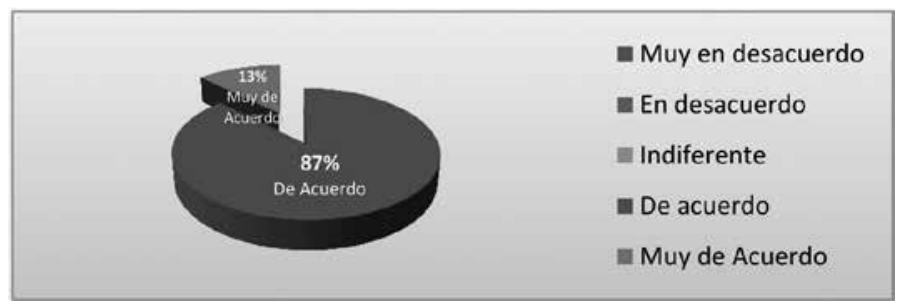

Fuente: Resultados del cuestionario en base al Libro Coso II. Elaboración Propia.

La identificación de procesos, subprocesos y etapas es una labor que los servicios deberían tener realizada y respaldada a través de documentos formales, en este caso que un $87 \%$ afirme estar de acuerdo y un $13 \%$ muy de acuerdo, asegura que los funcionarios de auditoria interna, tiene identificados sobre bases técnicas, términos de referencia y normativas internas sus procesos. 


\section{Grafico №7: Prioriza los procesos críticos}

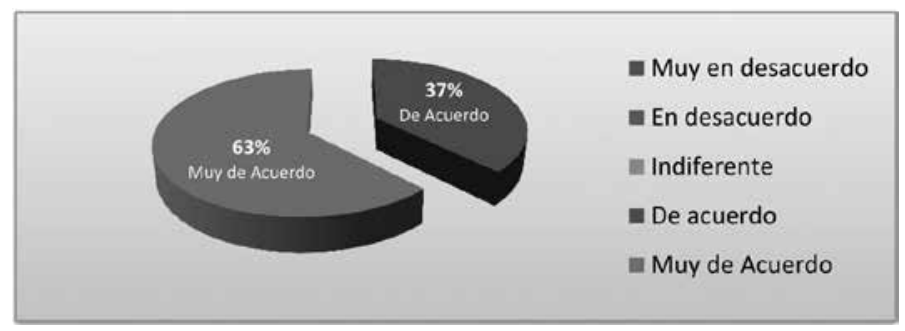

Fuente: Resultados del cuestionario en base al Libro Coso II. Elaboración Propia.

Para levantar información de los procesos, la técnica a utilizar para documentar y estructurar el trabajo es clave, por lo tanto que un $37 \%$ y $63 \%$ afirme estar de acuerdo y muy de acuerdo respectivamente, permite al personal definir el nivel de riesgos y eficiencia de los controles claves.

\section{Grafico No8: Identifica los subprocesos que componen los citados procesos} críticos.

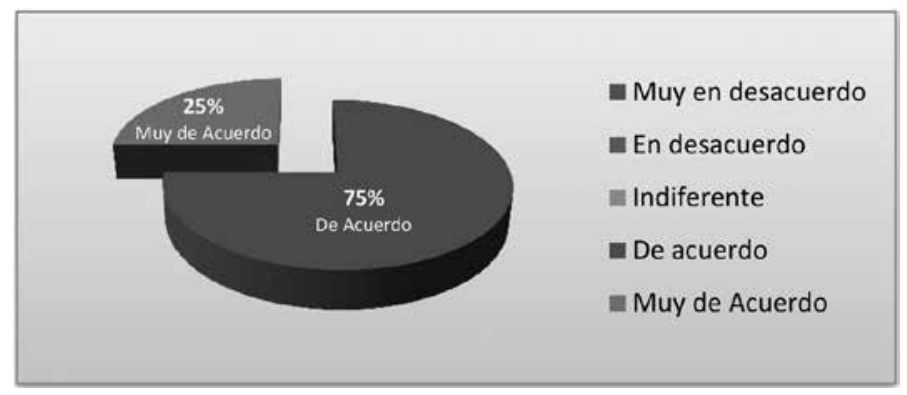

Fuente: Resultados del cuestionario en base al Libro Coso II. Elaboración Propia

Al igual que los procesos, los subprocesos que los componen pueden ser de diversa importancia y tener distinta influencia en la generación del servicio, un $75 \%$ y $25 \%$ asevera estar de acuerdo y muy de acuerdo respectivamente. 


\section{Grafico $\mathrm{N}^{\circ}$ 9: Pondera los subprocesos en relación a su importancia para el proceso crítico que componen.}

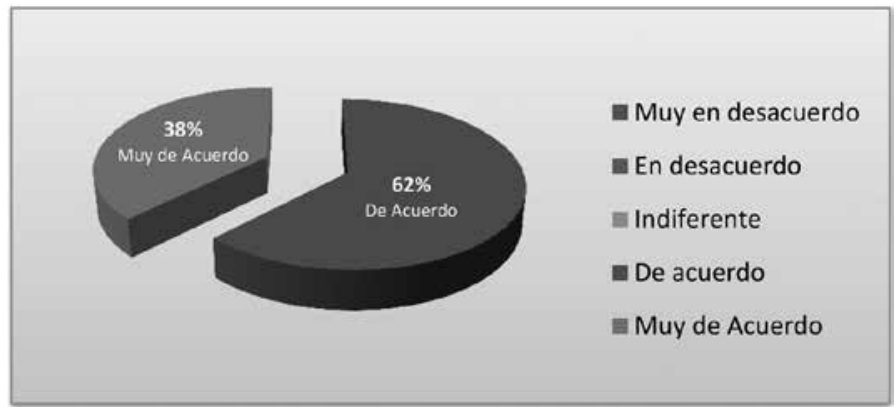

Fuente: Resultados del cuestionario en base al Libro Coso II. Elaboración Propia.

Para el análisis de los procesos críticos o relevantes en la institución pública en estudio, es necesario conocer el nivel en que afecta al cumplimiento del objetivo estratégico. Es por ello que si el $62 \%$ y $38 \%$ considera estar de acuerdo y muy de acuerdo respectivamente, con ponderar los subprocesos en relación a la importancia, que se realicen esquemas de relación y priorización de procesos relevantes.

\section{Grafico $N^{\circ} 10$ : Identifica las etapas que componen los subprocesos del proceso} crítico.

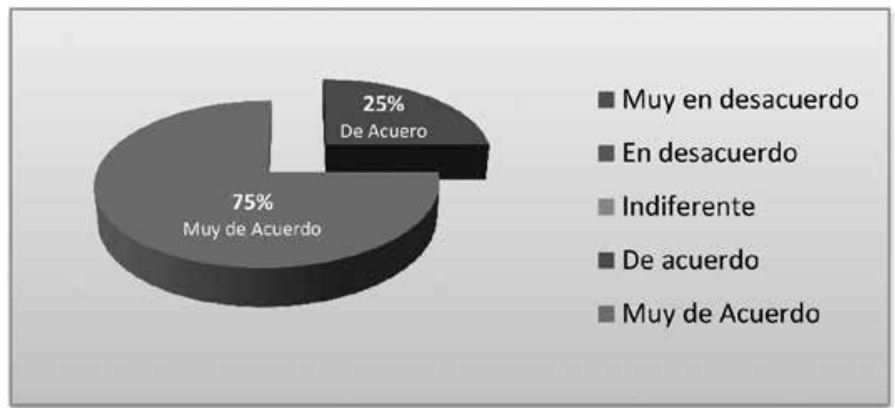

Fuente: Resultados del cuestionario en base al Libro Coso II. Elaboración Propia.

Esta variable depende claramente de la naturaleza y estructura de cada servicio, por lo tanto, si un $25 \%$ y $75 \%$ afirma estar de acuerdo y muy de acuerdo respectivamente, establece que se identifican las etapas que conforman los subprocesos. 


\section{Grafico N¹1: Identifica los objetivos que tienen cada etapa 0 subprocesos.}

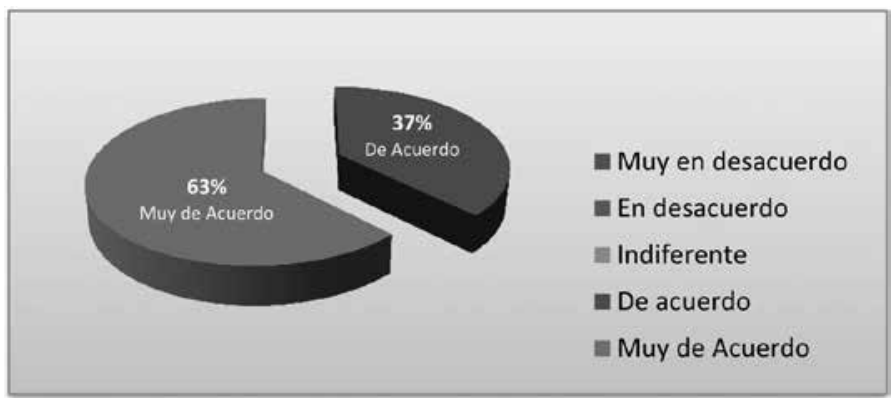

Fuente: Resultados del cuestionario en base al Libro Coso II. Elaboración Propia.

Los objetivos representan la finalidad que se persigue mediante la ejecución de una etapa o subproceso; si un $37 \%$ y $63 \%$ se encuentra de acuerdo y muy de acuerdo respectivamente, implica una labor de estudio y análisis de la documentación regulatoria y de soporte en los procesos, que efectúan los funcionarios del departamento de Auditoria Interna de la institución pública regional.

\section{Grafico $\mathrm{N}^{\circ}$ 12: Identifica los riesgos que pueden impedir 0 retrasar el logro de los objetivos.}

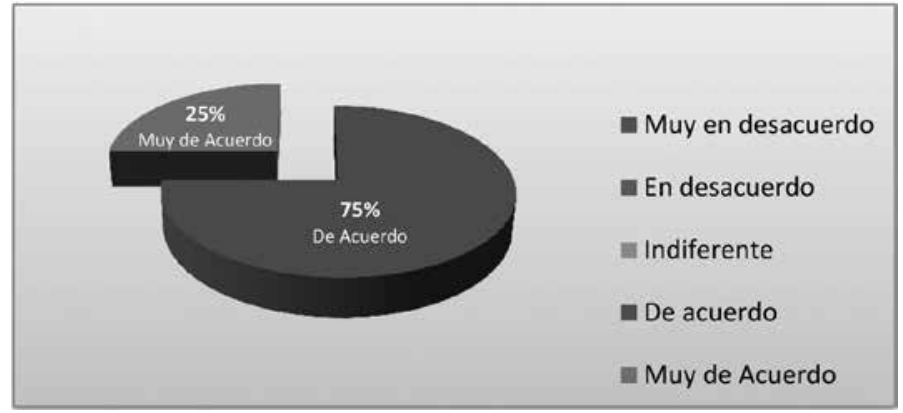

Fuente: Resultados del cuestionario en base al Libro Coso Il. Elaboración Propia.

Es necesario identificar los riesgos relevantes que se presentan asociados a los objetivos en cada proceso, subproceso y etapa. Por lo tanto un $75 \%$ y $25 \%$ aseveran estar de acuerdo y muy de acuerdo con la realización de esta actividad. 


\section{Grafico N¹3: Clasifica los riesgos por tipo y origen.}

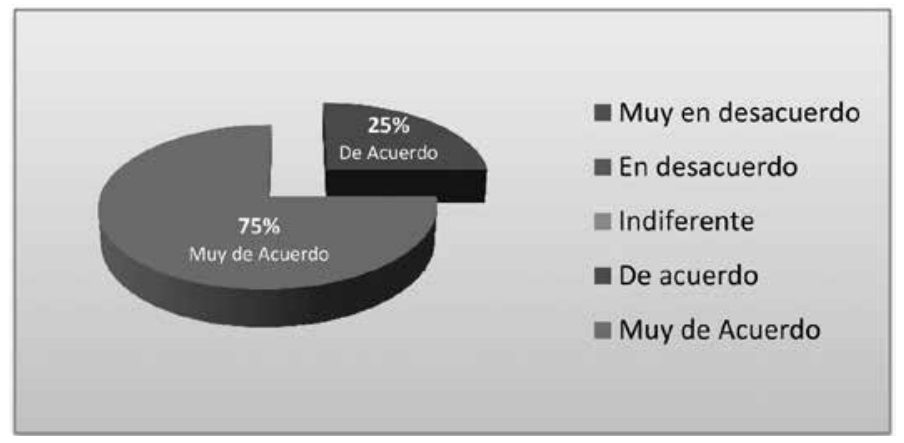

Fuente: Resultados del cuestionario en base al Libro Coso II. Elaboración Propia.

Si un $25 \%$ y $75 \%$ afirma está de acuerdo y muy de acuerdo respectivamente, con clasificar los riesgos de acuerdo a su tipo y origen, define que los funcionarios efectúan una medición del riesgo de acuerdo al nivel de severidad de este, evaluándolo en términos de probabilidad y posibilidad de ocurrencia

\section{Grafico №14: Identifica los controles claves asociados a los riesgos} identificados.

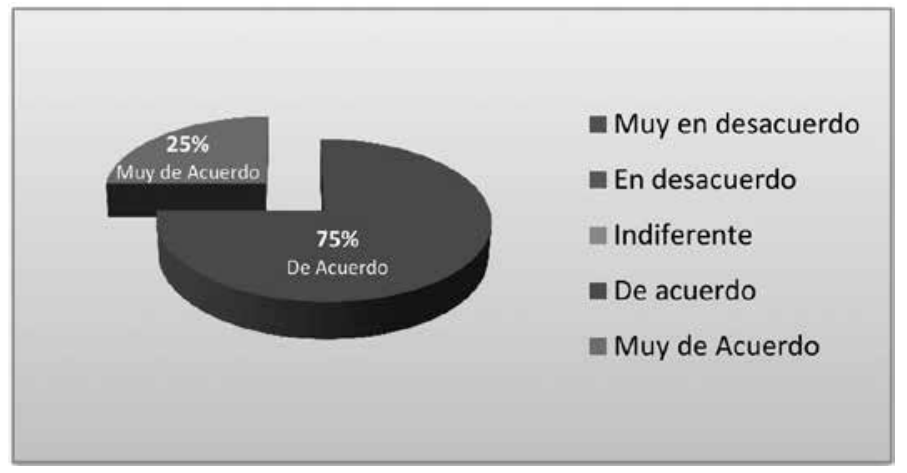

Fuente: Resultados del cuestionario en base al Libro Coso II. Elaboración Propia.

El reconocimiento y levantamiento de los controles claves que tiene el servicio consiste en la clasificación y calificación de los controles, según su oportunidad y periodicidad, cuyo objetivo principal es la mitigación de los riesgos. Por lo tanto si un $75 \%$ y $25 \%$ se encuentra de acuerdo y muy de acuerdo respectivamente, implica que los funcionarios enfocan sus acciones a la identificación de los controles claves. 


\section{Grafico N¹5: Evalúa los controles claves en relación a la efectividad de su diseño.}

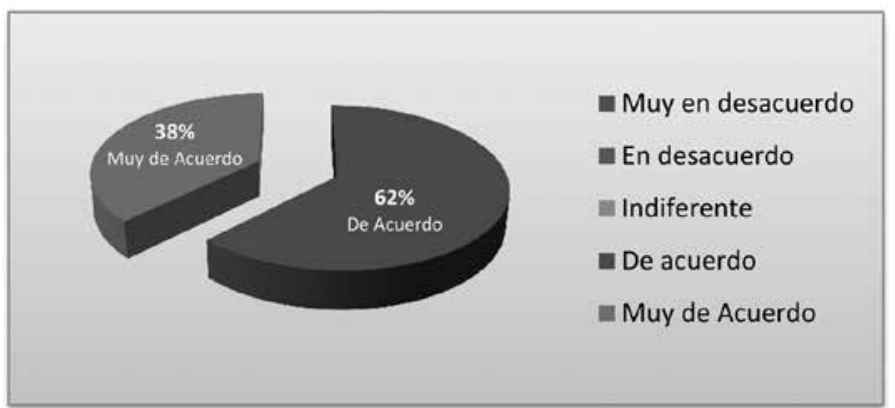

Fuente: Resultados del cuestionario en base al Libro Coso Il. Elaboración Propia.

Considerando que los funcionarios del departamento de auditoria interna identifican los controles claves, la tendencia hacia la evaluación de estos es muy similar, con un $62 \%$ y $38 \%$ que afirman estar de acuerdo y muy de acuerdo respectivamente, lo que evidencia que se genera una respuesta suficientemente adecuada para mantener la exposición del riesgo en un nivel aceptado.

\section{Grafico №16: Determinar la exposición al riesgo por riesgo, etapa, subproceso y proceso.}

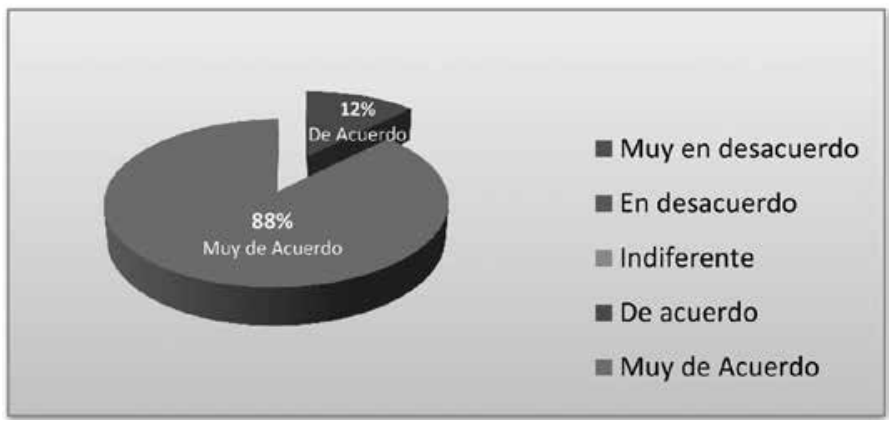

Fuente: Resultados del cuestionario en base al Libro Coso II. Elaboración Propia.

Definir la exposición al riesgo es una labor clave, ya que se identifican los controles efectivos a aplicar en cada riesgo en forma individual, en este caso si un $12 \%$ y $88 \%$ afirma estar de acuerdo y muy de acuerdo respectivamente, establece que los funcionarios efectúan estrategias para el tratamiento y monitoreo que permitan enfrentar el impacto o probabilidad oportunamente.

En relación a la información extraída de las preguntas restantes del cuestionario, cabe destacar que un porcentaje significativo afirma que las herramientas entregadas por la Guía Técnica №59 de Objetivo Gubernamental de Auditoría n² 
(2014) si bien, son efectivas, siempre va a existir un grado de vulnerabilidad, ante un posible fraude.

Mencionan además aquellos procesos que aportan de manera fundamental e importante al cumplimiento del objetivo estratégico de la organización que serán considerados para la matriz de riesgo, donde se destacan los siguientes;

1) Proceso de Control: Este proceso permite a la organización vigilar el desempeño y realizar acciones correctivas, cuando las cosas no están marchando de acuerdo a lo planeado.

2) Proceso Administrativo: Este proceso permite planificar, organizar y controlar los objetivos estratégicos dentro de la organización.

3) Proceso Recursos Humanos: Enrola empleados competentes y motivados por su trabajo.

Por otra parte, se señalan los procesos que aportan en menor forma al cumplimiento del objetivo estratégico de la organización que son: Proceso de Estudios e Investigaciones; Proceso de Infraestructura.

\section{Matriz de Riesgos Estratégica.}

Para dar cumplimiento al segundo objetivo planteado, se realizó el análisis de la Matriz de Riesgos Estratégica, que tiene como finalidad proporcionar las principales situaciones de potenciales riesgos de fraude al interior de la institución pública regional.

La Matriz de riesgos estratégica confeccionada por los funcionarios de la institución en estudio, tiene 3 procesos transversales que presentan situaciones de riesgos, estos son; Recursos Humanos, Iniciativas de Inversión y Transferencias a/de otras entidades públicas, los cuales tienden a desglosarse en sub-procesos y etapas.

Al revisar esta matriz se identificaron 77 etapas en total, las cuales 32 corresponden a recursos humanos, 26 a iniciativas de inversión y tan solo 19 a transferencias a/ de otras entidades públicas, en donde se tomaron 5 etapas de cada proceso que es presentado a continuación y se divide en cuatro grandes secciones:

1. Identifica el proceso que genera una situación de Riesgo.

2. Descripción especifica del riesgo respecto a su probabilidad, impacto severidad.

3. Define los Controles claves y clasifica el riesgo entregándole una 
ponderación.

4. Finalmente, se entrega el valor y clasificación de la exposición al riesgo ponderada la cual se divide en riesgo crítico, etapa, subproceso y proceso.

Además se confeccionaron 3 cuadros resúmenes de cada proceso.

$1^{\circ}$ Identifica el proceso que genera una situación de Riesgo.

- $\quad$ Proceso Transversal Recursos Humanos por Sub-proceso y Etapas

\begin{tabular}{|c|c|c|c|c|c|}
\hline $\begin{array}{l}\text { PROCESO } \\
\text { TRANSVERSAL }\end{array}$ & $\begin{array}{l}\text { PROCESO } \\
\text { CRITICO }\end{array}$ & SUBPROCESO & $\begin{array}{l}\text { PONDERACION } \\
\text { ESTRATÉGICA } \\
\text { SUBPROCESO }\end{array}$ & ETAPAS & OBJETIVOS \\
\hline $\begin{array}{l}\text { RECURSOS } \\
\text { HUMANOS }\end{array}$ & $\begin{array}{l}\text { RECURSOS } \\
\text { HUMANOS }\end{array}$ & $\begin{array}{l}\text { Evaluación de } \\
\text { Desempeño }\end{array}$ & 0,15 & Calificación & $\begin{array}{l}\text { Calificar objetivamente } \\
\text { el desempeño de los } \\
\text { funcionarios dentro } \\
\text { de los plazos que } \\
\text { estipula el proceso. }\end{array}$ \\
\hline $\begin{array}{l}\text { RECURSOS } \\
\text { HUMANOS }\end{array}$ & $\begin{array}{l}\text { RECURSOS } \\
\text { HUMANOS }\end{array}$ & $\begin{array}{l}\text { Evaluación de } \\
\text { Desempeño }\end{array}$ & 0,15 & Evaluación & $\begin{array}{l}\text { Evaluar } \\
\text { permanentemente } \\
\text { el desempeño de } \\
\text { los funcionarios, } \\
\text { de acuerdo al } \\
\text { perfil de cargo por } \\
\text { competencias, } \\
\text { incentivando el } \\
\text { mejoramiento de su } \\
\text { trabajo Individual y en } \\
\text { Equipo. }\end{array}$ \\
\hline $\begin{array}{l}\text { RECURSOS } \\
\text { HUMANOS }\end{array}$ & $\begin{array}{l}\text { RECURSOS } \\
\text { HUMANOS }\end{array}$ & $\begin{array}{l}\text { Evaluación de } \\
\text { Desempeño }\end{array}$ & 0,15 & Apelación & $\begin{array}{l}\text { Dar cumplimiento } \\
\text { a la normativa } \\
\text { y al derecho del } \\
\text { funcionario a } \\
\text { manifestar su } \\
\text { desacuerdo. }\end{array}$ \\
\hline $\begin{array}{l}\text { RECURSOS } \\
\text { HUMANOS }\end{array}$ & $\begin{array}{l}\text { RECURSOS } \\
\text { HUMANOS }\end{array}$ & $\begin{array}{l}\text { Higiene y } \\
\text { Seguridad }\end{array}$ & 0,15 & $\begin{array}{l}\text { Evaluación } \\
\text { del avance } \\
\text { del Plan de } \\
\text { trabajo }\end{array}$ & $\begin{array}{l}\text { Efectuar análisis } \\
\text { del cumplimiento } \\
\text { o no cumplimiento } \\
\text { de actividades y su } \\
\text { justificación para } \\
\text { adopción de medidas } \\
\text { correctivas. }\end{array}$ \\
\hline $\begin{array}{l}\text { RECURSOS } \\
\text { HUMANOS }\end{array}$ & $\begin{array}{l}\text { RECURSOS } \\
\text { HUMANOS }\end{array}$ & $\begin{array}{l}\text { Higiene y } \\
\text { Seguridad }\end{array}$ & 0,15 & $\begin{array}{l}\text { Diagnóstico } \\
\text { de prevención } \\
\text { de riesgo y } \\
\text { mejoramiento } \\
\text { de las } \\
\text { condiciones } \\
\text { de trabajo. }\end{array}$ & $\begin{array}{l}\text { Evaluar el espacio } \\
\text { físico a fin de } \\
\text { detectar deficiencias } \\
\text { de acuerdo a la } \\
\text { normativa vigente. }\end{array}$ \\
\hline
\end{tabular}




\section{- $\quad$ Proceso Transversal de Iniciativas de Inversión por Sub-proceso y}

\section{Etapas}

\begin{tabular}{|c|c|c|c|c|c|}
\hline $\begin{array}{l}\text { PROCESO } \\
\text { TRANSVERSAL }\end{array}$ & $\begin{array}{l}\text { PROCESO } \\
\text { CRITICO }\end{array}$ & SUBPROCESO & $\begin{array}{l}\text { PONDERACION } \\
\text { ESTRATÉGICA } \\
\text { SUBPROCESO }\end{array}$ & ETAPAS & $\begin{array}{l}\text { PROCESO } \\
\text { TRANSVERSAL }\end{array}$ \\
\hline $\begin{array}{l}\text { Iniciativas de } \\
\text { inversión }\end{array}$ & $\begin{array}{l}\text { EJECUCIÓN } \\
\text { DE LA } \\
\text { INVERSIÓN }\end{array}$ & $\begin{array}{l}\text { Seguimiento } \\
\text { Administrativo } \\
\text { y Financiero } \\
\text { de las } \\
\text { Iniciativas de } \\
\text { Inversión }\end{array}$ & 0,3 & $\begin{array}{l}\text { Revisión y } \\
\text { Aprobación } \\
\text { de Estados de } \\
\text { Pago }\end{array}$ & $\begin{array}{l}\text { Verificar el } \\
\text { avance efectivo } \\
\text { del proyecto, } \\
\text { con relación al } \\
\text { monto contratado } \\
\text { y al cronograma } \\
\text { de actividades } \\
\text { propuesto }\end{array}$ \\
\hline $\begin{array}{l}\text { Iniciativas de } \\
\text { inversión }\end{array}$ & $\begin{array}{l}\text { EJECUCIÓN } \\
\text { DE LA } \\
\text { INVERSIÓN }\end{array}$ & $\begin{array}{l}\text { Seguimiento } \\
\text { Administrativo } \\
\text { y Financiero } \\
\text { de las } \\
\text { Iniciativas de } \\
\text { Inversión }\end{array}$ & 0,3 & $\begin{array}{l}\text { Control de las } \\
\text { Modificaciones } \\
\text { de Contrato, } \\
\text { tanto en el } \\
\text { monto como en } \\
\text { el plazo }\end{array}$ & $\begin{array}{l}\text { Constatar que la } \\
\text { modificación (Plazo- } \\
\text { Presupuesto) ha } \\
\text { sido debidamente } \\
\text { aprobada, conforme } \\
\text { a la normativa } \\
\text { vigente }\end{array}$ \\
\hline $\begin{array}{l}\text { Iniciativas de } \\
\text { inversión }\end{array}$ & $\begin{array}{l}\text { EJECUCIÓN } \\
\text { DE LA } \\
\text { INVERSIÓN }\end{array}$ & $\begin{array}{l}\text { Seguimiento } \\
\text { Administrativo } \\
\text { y Financiero } \\
\text { de las } \\
\text { Iniciativas de } \\
\text { Inversión }\end{array}$ & 0,3 & $\begin{array}{l}\text { Revisión de } \\
\text { informes de } \\
\text { Asesores } \\
\text { Técnicos de } \\
\text { Obras }\end{array}$ & $\begin{array}{l}\text { Evaluar } \\
\text { técnicamente el } \\
\text { informe del Asesor } \\
\text { Técnico de Obras } \\
\text { para visar el pago } \\
\text { respectivo }\end{array}$ \\
\hline $\begin{array}{l}\text { Iniciativas de } \\
\text { inversión }\end{array}$ & $\begin{array}{l}\text { EJECUCIÓN } \\
\text { DE LA } \\
\text { INVERSIÓN }\end{array}$ & $\begin{array}{l}\text { Licitación y } \\
\text { contratación }\end{array}$ & 0,4 & $\begin{array}{l}\text { Suscripción del } \\
\text { contrato }\end{array}$ & $\begin{array}{l}\text { Dar inicio a la } \\
\text { ejecución de las } \\
\text { iniciativas de } \\
\text { inversión }\end{array}$ \\
\hline $\begin{array}{l}\text { Iniciativas de } \\
\text { inversión }\end{array}$ & $\begin{array}{l}\text { EJECUCIÓN } \\
\text { DE LA } \\
\text { INVERSIÓN }\end{array}$ & $\begin{array}{l}\text { Licitación y } \\
\text { contratación }\end{array}$ & 0,4 & $\begin{array}{l}\text { Gestionar } \\
\text { incrementos } \\
\text { presupuestarios } \\
\text { cuando } \\
\text { corresponda }\end{array}$ & $\begin{array}{l}\text { Lograr la } \\
\text { adjudicación de } \\
\text { la iniciativa de } \\
\text { inversión }\end{array}$ \\
\hline
\end{tabular}


- $\quad$ Proceso Transversal de Transferencias a/de otras entidades públicas por Sub-proceso y Etapas

\begin{tabular}{|c|c|c|c|c|c|}
\hline $\begin{array}{l}\text { PROCESO } \\
\text { TRANSVERSAL }\end{array}$ & $\begin{array}{l}\text { PROCESO } \\
\text { CRITICO }\end{array}$ & SUBPROCESO & $\begin{array}{l}\text { PONDERACION } \\
\text { ESTRATÉGICA } \\
\text { SUBPROCESO }\end{array}$ & ETAPAS & OBJETIVOS \\
\hline $\begin{array}{l}\text { Transferencias } \\
\text { a/de otras } \\
\text { entidades } \\
\text { públicas }\end{array}$ & $\begin{array}{l}\text { Diseño y } \\
\text { Postulación }\end{array}$ & $\begin{array}{l}\text { Diseño de las } \\
\text { bases }\end{array}$ & 0,3 & $\begin{array}{l}\text { Elaboración } \\
\text { de las Bases } \\
\text { del concurso }\end{array}$ & $\begin{array}{l}\text { Establecer criterios } \\
\text { para la postulación, } \\
\text { la distribución } \\
\text { presupuestaria } \\
\text { y evaluación del } \\
\text { concurso }\end{array}$ \\
\hline $\begin{array}{l}\text { Transferencias } \\
\text { a/de otras } \\
\text { entidades } \\
\text { públicas }\end{array}$ & $\begin{array}{l}\text { Diseño y } \\
\text { Postulación }\end{array}$ & $\begin{array}{l}\text { Diseño de las } \\
\text { bases }\end{array}$ & 0,3 & $\begin{array}{l}\text { Recepción de } \\
\text { Bases }\end{array}$ & $\begin{array}{l}\text { Dar visto bueno a las } \\
\text { Bases del concurso }\end{array}$ \\
\hline $\begin{array}{l}\text { Transferencias } \\
\text { a/de otras } \\
\text { entidades } \\
\text { públicas }\end{array}$ & $\begin{array}{l}\text { Diseño y } \\
\text { Postulación }\end{array}$ & $\begin{array}{l}\text { Lineamientos } \\
\text { y Planificación } \\
\text { FIC-R }\end{array}$ & 0,4 & $\begin{array}{l}\text { Recepción de } \\
\text { documentos } \\
\text { presupuesto }\end{array}$ & $\begin{array}{l}\text { Conocer con } \\
\text { certeza cuál es la } \\
\text { distribución de los } \\
\text { montos disponibles } \\
\text { para realizar las } \\
\text { gestiones del Fondo } \\
\text { de Innovación para la } \\
\text { competitividad. }\end{array}$ \\
\hline $\begin{array}{l}\text { Transferencias } \\
\text { a/de otras } \\
\text { entidades } \\
\text { públicas }\end{array}$ & $\begin{array}{l}\text { Diseño y } \\
\text { Postulación }\end{array}$ & $\begin{array}{l}\text { Lineamientos } \\
\text { y Planificación } \\
\text { FIC-R }\end{array}$ & 0,4 & $\begin{array}{l}\text { Reuniones } \\
\text { bilaterales } \\
\text { con Agencias } \\
\text { Ejecutoras } \\
\text { para } \\
\text { presentación } \\
\text { de propuestas }\end{array}$ & $\begin{array}{l}\text { Lograr que los } \\
\text { objetivos de } \\
\text { los programas } \\
\text { implementados } \\
\text { por las Agencias } \\
\text { Ejecutoras estén } \\
\text { enmarcados en } \\
\text { los ejes de la } \\
\text { estrategia regional de } \\
\text { innovación. }\end{array}$ \\
\hline $\begin{array}{l}\text { Transferencias } \\
\text { a/de otras } \\
\text { entidades } \\
\text { públicas }\end{array}$ & $\begin{array}{l}\text { Diseño y } \\
\text { Postulación }\end{array}$ & $\begin{array}{l}\text { Lineamientos } \\
\text { y Planificación } \\
\text { FIC-R }\end{array}$ & 0,4 & $\begin{array}{l}\text { Analizar y } \\
\text { elaborar } \\
\text { propuesta de } \\
\text { distribución } \\
\text { de los } \\
\text { recursos }\end{array}$ & $\begin{array}{l}\text { Las propuestas } \\
\text { analizadas y } \\
\text { elaboradas, tengan } \\
\text { una base sólida y } \\
\text { sustentable. }\end{array}$ \\
\hline
\end{tabular}


$2^{\circ}$ Descripción especifica del riesgo respecto a su probabilidad, impacto y severidad.

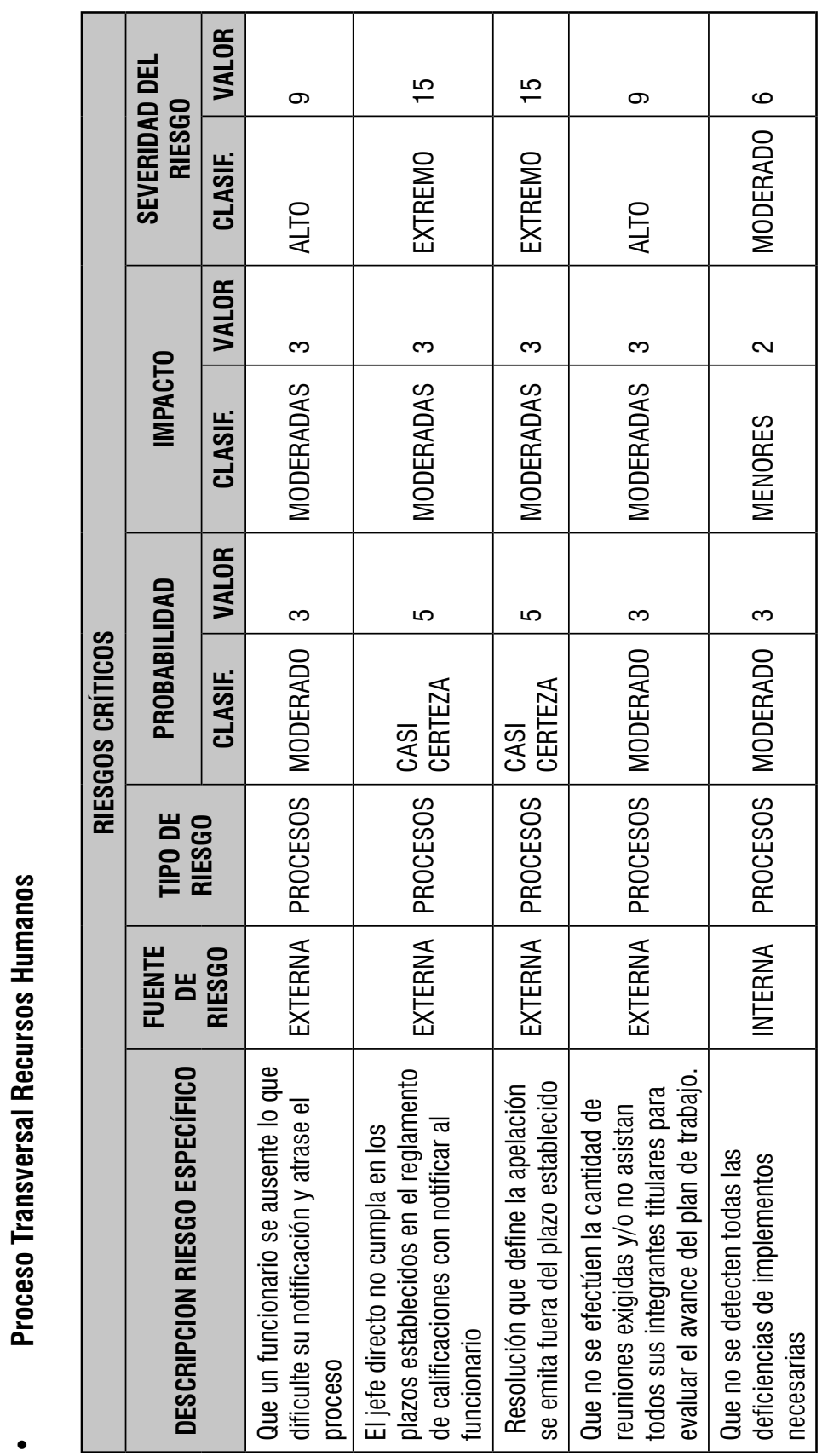




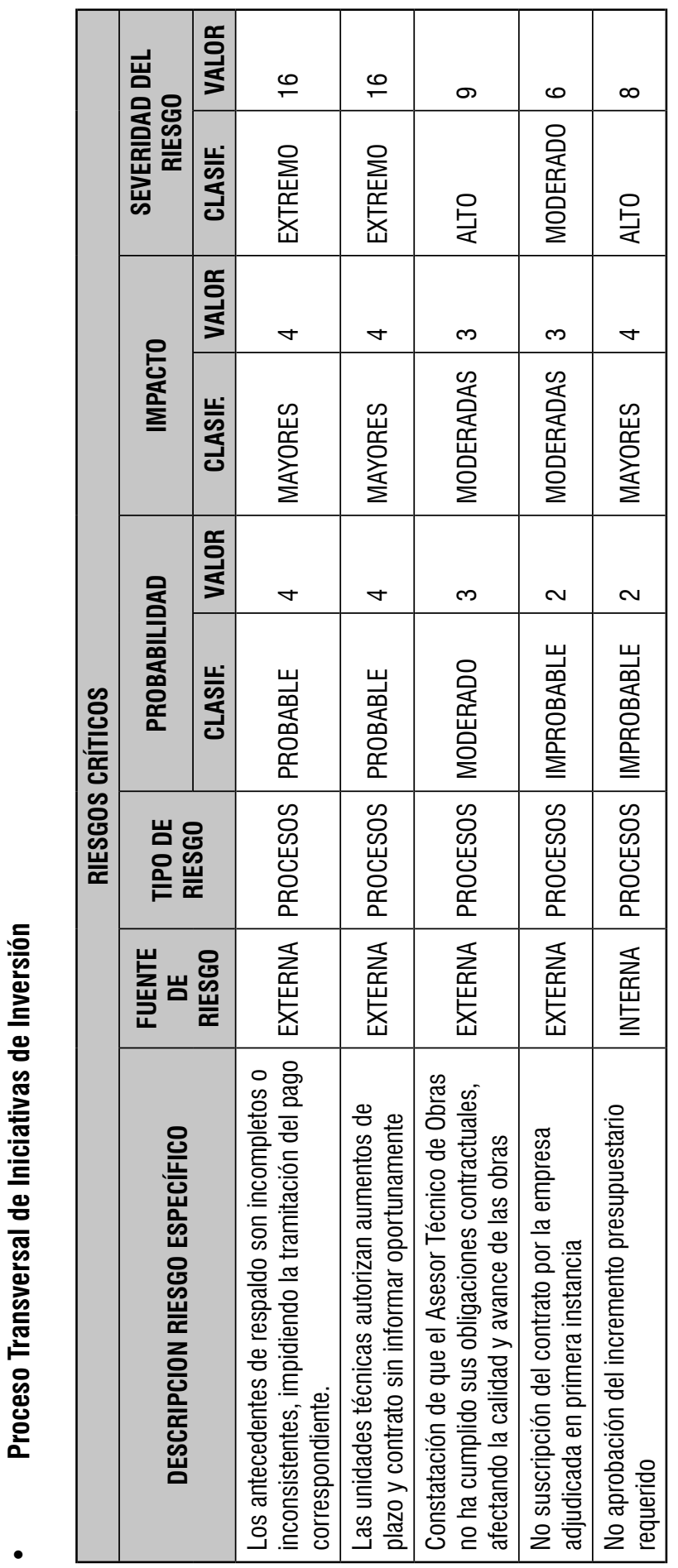




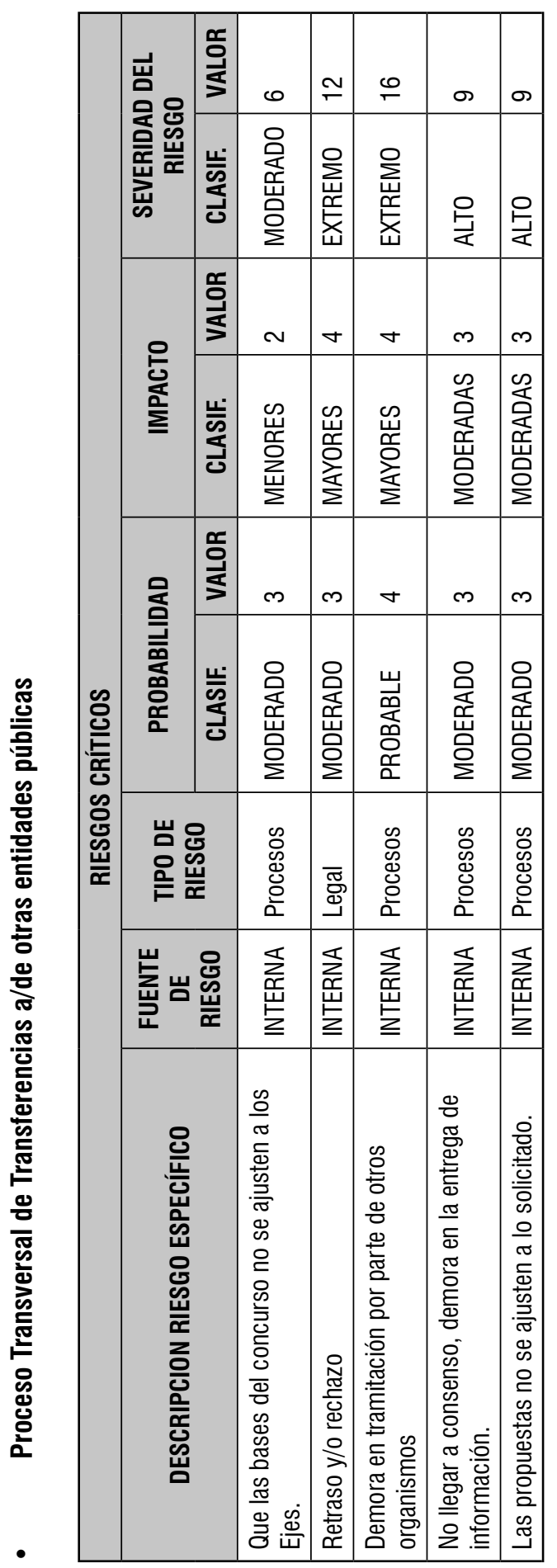




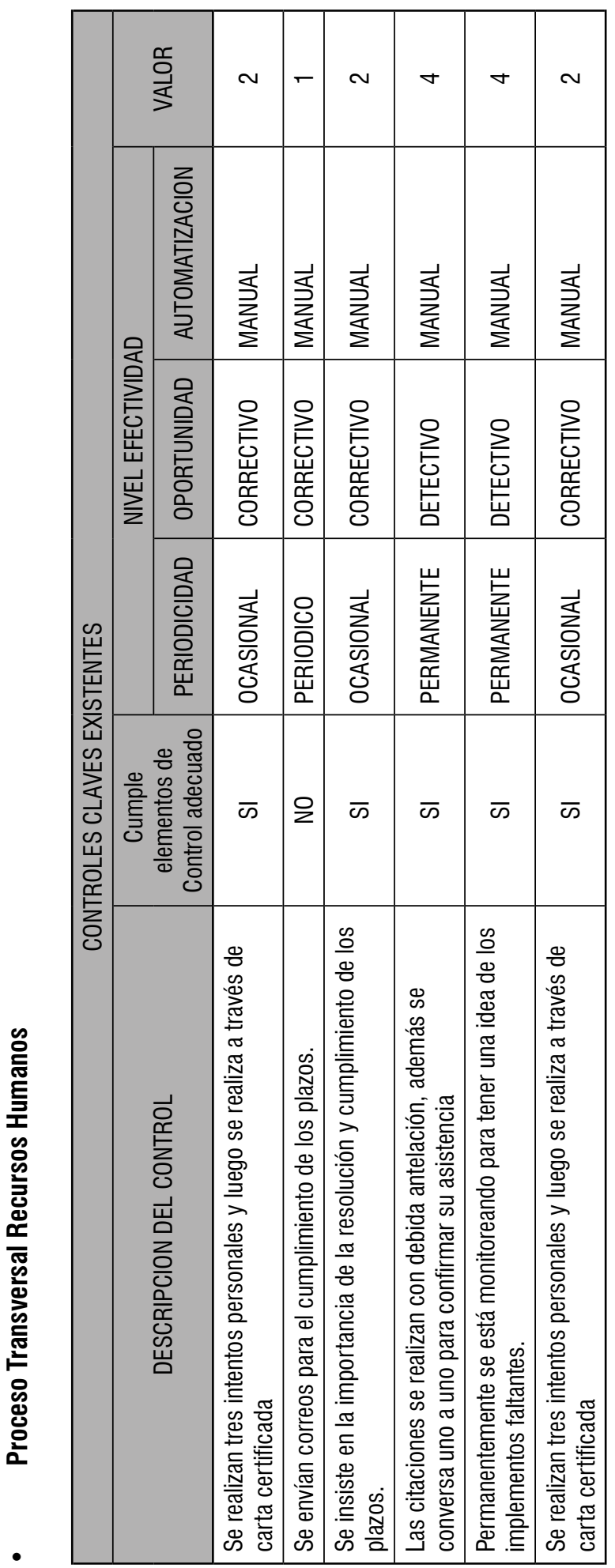




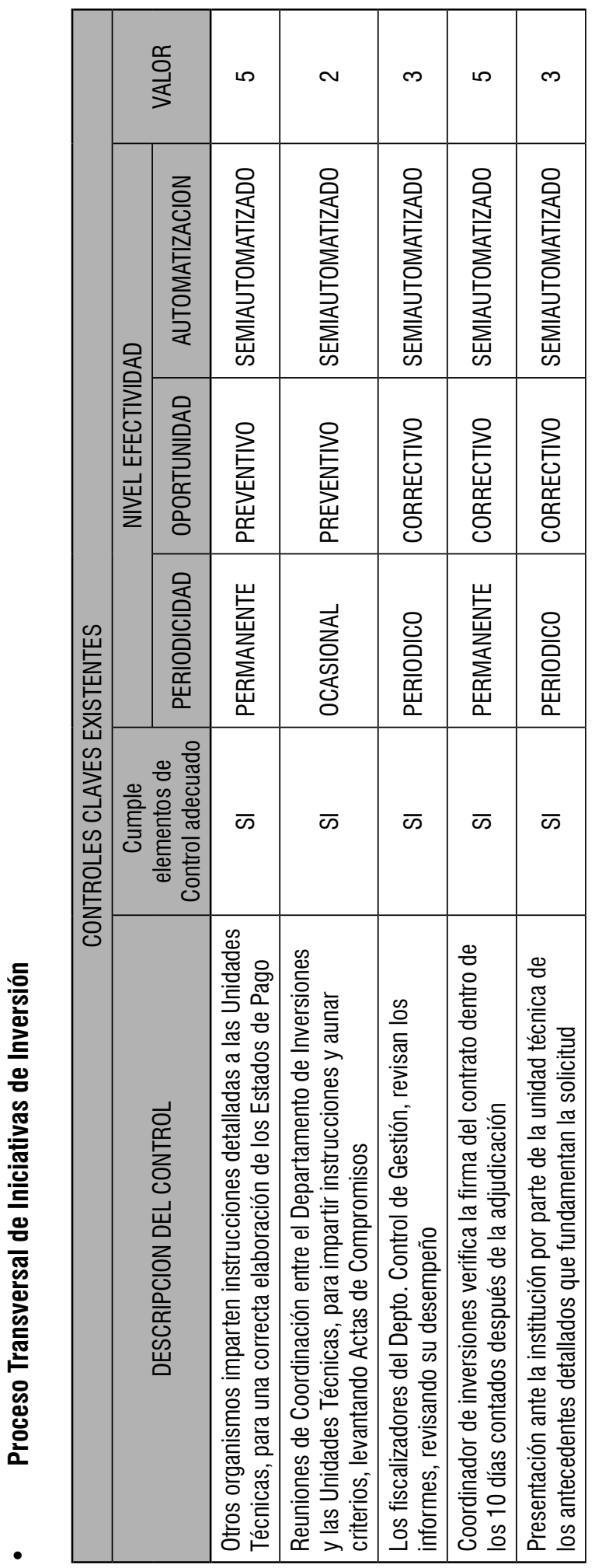




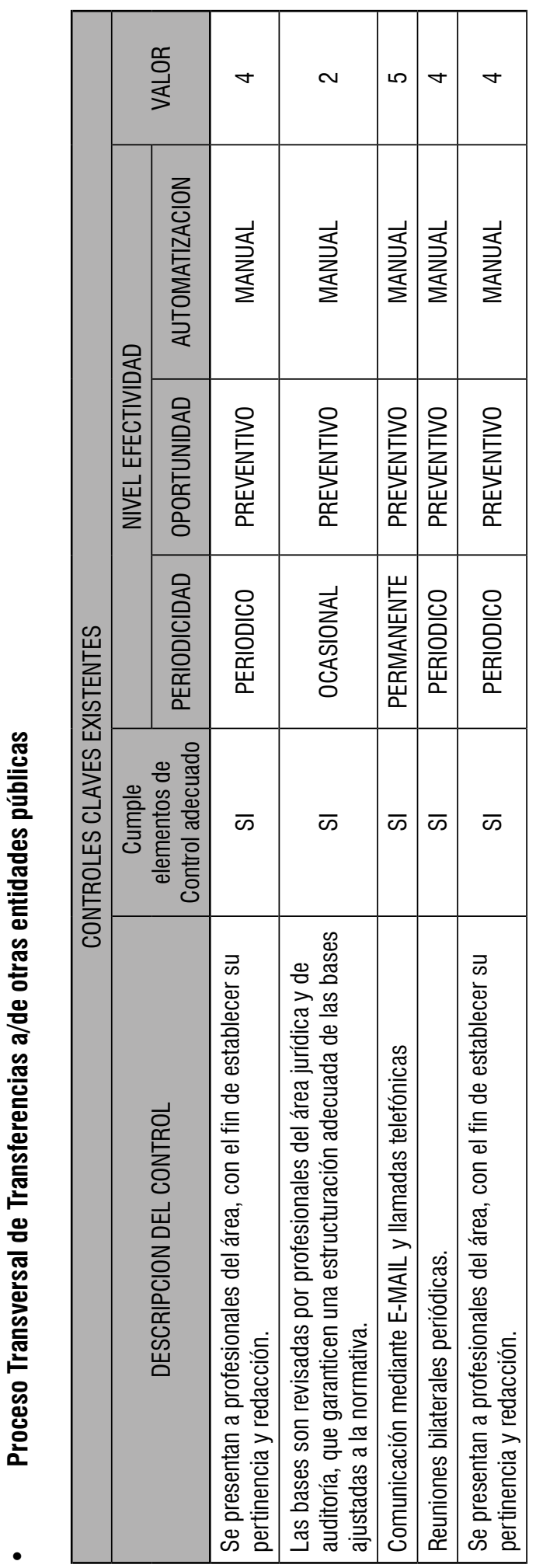




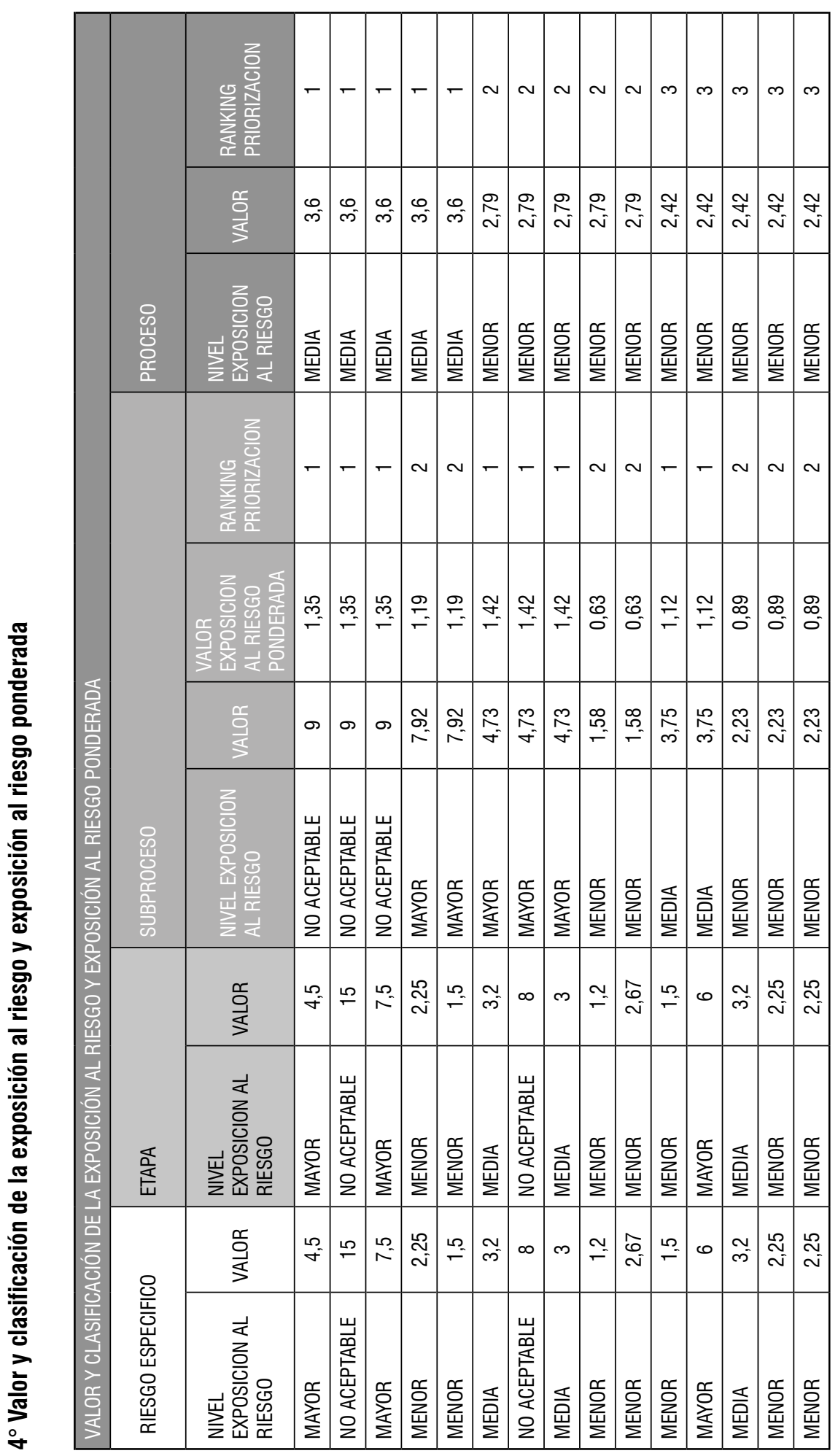




\section{CONCLUSIONES.}

La investigación desarrollada ha permitido, a través del análisis y discusión de los instrumentos aplicados, evaluar la implementación de una gestión de riesgos de fraude basada según el marco integrado del Libro Coso II, a una institución pública regional, durante el periodo 2014, lo que contribuye y permite señalar lo siguiente: en esta base a los antecedentes obtenidos en la aplicación de los cuestionarios, a los funcionarios de la institución en estudio, la tendencia es favorable respecto al cumplimiento del levantamiento de los procesos, subprocesos y etapas críticas que presentan situaciones de riesgos, afirmando que se efectúan las siguientes actividades:

- Identifican los riesgos, realizando un proceso de búsqueda, reconocimiento y descripción de este.

- Confeccionan análisis que permitan comprender la naturaleza del riesgo y determinar su nivel.

- Priorizan mediante un ranking los riesgos analizados.

- Determinan un tratamiento y/o monitoreo, desarrollando e implementando estrategias, que mantengan el riesgo dentro de los niveles aceptados por la organización.

En relación a la información obtenida respecto a la efectividad de la guía técnica No59 de Objetivo Gubernamental de Auditoría No 2 (2014), cabe destacar que un porcentaje significativo afirma que las herramientas entregadas por este documento, si bien, son efectivas, siempre va a existir un grado de vulnerabilidad, ante un posible fraude.

La indagación además señala que los principales riesgos de acuerdo a la Matriz, son los identificados en el proceso de Recursos Humanos, Iniciativas de Inversión y Transferencias a/de otras entidades públicas, en base a los criterios utilizados en la preparación del instrumento mencionado.

En cuanto a la función de auditoría interna, es un actor principal en las actividades antifraude y que sirve de apoyo a promover un enfoque basado en prevenir, detectar y responder ante fraudes y conductas irregulares. Tales responsabilidades representan un importante cambio en comparación con el papel más tradicional de la auditoría interna, enfocada principalmente al cumplimiento del control interno. También se debe tener en consideración la necesidad de fomentar el desarrollo de una auditoria interna responsable de:

- Planificar y llevar a cabo la evaluación del diseño y la efectividad operativa 
de los controles antifraude.

- Ayudar a la organización en la evaluación de los riesgos de fraude y obtener sacar conclusiones en cuanto a las estrategias más apropiadas para mitigarlos.

- Informar al Comité de Auditoría sobre las evaluaciones del control interno, auditorías, investigaciones y actividades relacionadas.

Finalmente la investigación evidenció que la institución en su aplicación de la gestión de riesgos, está de acuerdo a los criterios establecidos en el Libro Coso II en gran parte de la ejecución de los componentes del Control Interno. Además durante el periodo 2014 realizó la identificación, el análisis, la valorización de los riesgos críticos y la formulación de las medidas de tratamiento de dichos riesgos en base a lo establecido en la Guía Técnica ํㅜ 59 de Objetivo Gubernamental de Auditoría No 2 (2014), cuyo marco metodológico para la gestión de riesgos está basado principalmente en las disposiciones de las Normas Chilenas NCh-ISO 31000:2012, NCh-ISO 31000:2013 y en menor medida el Libro Coso I y Coso II.

Es de vital importancia mencionar también, que pese a contar con herramientas para mitigar las situaciones potenciales de riesgos de fraude, como la matriz de riesgos estratégica y su plan de tratamiento, en que ambas contribuyen de manera integral al proceso de gestión de riegos, es preciso fortalecer el desarrollo de un programa antifraude específico para procesos que involucren el manejo 0 la transferencia de efectivo o efectivo equivalente, definiendo una Matriz de Riesgos Especificado donde se puedan generar este tipo de fraude. 


\section{BIBLIOGRAFÍA.}

- American Institute of Certified Public Accountant (2012) NAGA 63, Sección 240." Consideracion de fraude en una auditoria de estados financieros"

- Arens, A (1996). Auditoria un Enfoque Integral. Editorial Prentice Hall, México.

- Cepeda, G. (1997) Auditoría y Control Interno. Editorial McGrawhill, Colombia.

- Colegio de Contadores de Chile A.G (2012) Normas de Auditoria Interna, NORMA No3 "Glosario de términos y conceptos de auditoría interna y de gestión". Chile

- Colegio de Contadores de Chile A.G., (2013) Nomas de Auditoria Interna, NORMA N4 "Normas generales de auditoría interna y de gestión". Chile.

- Colegio de Contadores de Chile A.G., (2013) Nomas de Auditoria Interna, NORMA N5 "Normas de conducta de los auditores internos y de gestión". Chile.

- Colegio de Contadores de Chile A.G., (2013) Nomas de Auditoria Interna, NORMA Nº "Definición de Auditoría Interna y de Gestión”. Chile.

- Colegio de Contadores de Chile A.G., (2013) Nomas de Auditoria Interna, NORMA N`7 "Informes de Auditoría Interna y de Gestión”. Chile.

- Coopers \& Lybrand (1997) "Los nuevos conceptos del control Interno" Informe Coso, Editorial Díaz de Santos.

- Gobierno de Chile (2014) Guía Técnica n54 Objetivo Gubernamental de Auditoría n². "Mantención y mejoramiento de las actividades asociadas al proceso de gestión de riesgos en el Estado". Santiago de Chile.

- Instituto Nacional de Normalización, (2012) Norma Chilena NCh-ISO 31000:2012 Gestión del riesgo - Principios y orientaciones.

- KPMG Auditores Consultores Chile. Revista de Investigación. "Gestión de Riesgos de Fraude, desarrollo de una estrategia de prevención, detección y respuesta al fraude". Chile.

- Labrada, V (2010) Etica en los Negocios. Madrid; Editorial ESIC. 
- Sponsoring Organizations of the Treadway Commission (2004) Gestión de Riesgos Corporativos, Marco Integrado -Técnicas de aplicación. 